\title{
FORMAÇÃO DE PROFESSORES E EDUCAÇÃO AMBIENTAL NA ESCOLA PÚBLICA: CONTRIBUIÇÕES DA PEDAGOGIA HISTÓRICO-CRÍTICA
}

\author{
Jorge Sobral da Silva Maia \\ Universidade Estadual do Norte do Paraná - UENP \\ sobralmaia@uenp.edu.br \\ Lucas André Teixeira. \\ Universidade Estadual Paulista - UNESP \\ lucasandreteixeira@gmail.com
}

\begin{abstract}
RESUMO
Ao conceber a educação ambiental como uma forma de contextualizar as relações entre sociedade e natureza na educação, entende-se que a prática educativa ambiental na escola requer formação que possibilite ao professor se instrumentalizar para o enfrentamento pedagógico da questão ambiental. Partindo desta necessidade, e considerando que a educação ambiental não se restringe às ações fragmentadas e pontuais de tematização do ambiente na educação, este artigo apresenta os resultados de um estudo que buscou, fundamentado na Pedagogia Histórico-Crítica, contextualizar e problematizar a formação de professores para a educação ambiental na escola pública. Para isso, com o objetivo de empreender uma análise crítica das bases que fundamentam a produção acadêmica e científica sobre Formação de Professores, buscamos contribuir com a construção de uma concepção sócio-histórica para a Formação de Professores como educadores ambientais. Palavras-chave: Educação Ambiental; Formação de Professores; Pedagogia HistóricoCrítica.
\end{abstract}

\section{TEACHER EDUCATION AND ENVIRONMENTAL EDUCATION AT PUBLIC SCHOOL: CONTRIBUTIONS OF HISTORICAL-CRITICAL PEDAGOGY}

\begin{abstract}
Once we conceive environmental education as a way to contextualize the relations between society and nature, we understand that the environmental educational practices at school require an education which enables the teacher to get instrumentalized to pedagogically cope with the environmental question. From this necessity and considering that environmental education is not restricted to the fragmented and punctual action of thematization of the environmental in education, this article presents the results of a study that sought to contextualize and problematize the teacher education to environmental education at public school, based on the Historical-Critical Pedagogy. To do so, we sought to contribute to the construction of a socio-historical approach to Teacher Education as environmental educators by critically analyzing the bases that justify the academic and scientific production about Teacher Education.

Keywords: Environmental Education; Teacher Education; Historical-Critical Pedagogy.
\end{abstract}

\section{Introdução ao método e procedimentos}

Dentre os principais estudos produzidos no Brasil sobre a pesquisa em educação ambiental (EA), pode-se observar certo consenso quanto à definição de que a EA é, antes de tudo, educação (GRÜN, 2007; LOUREIRO, 2004; TOZONI-REIS, 2004). Isto vincula a EA, especificamente, ao enfrentamento pedagógico da questão ambiental, pois a 
pedagogia "como ciência da e para a educação, se preocupa com a compreensão teórica e prática dos processos educativo-formativos e diz respeito aos saberes e modos da ação voltados para a formação humana" (TOZONI-REIS, 2007, p. 186).

Embora reconheçamos a trajetória da EA no Brasil como representativa de uma área do conhecimento que se consolidou, entendemos que o processo de inserção da EA na educação escolar ainda carece de discussões críticas para superar práticas educativas e pedagógicas pautadas na apropriação distorcida, simplificadora e reducionista dos, muitas vezes, agentes causadores dos problemas ambientais que observamos hoje. Essa prática educativa ambiental poderia ser considerada uma prática que Saviani (2005) definiu como sendo "crítico-reprodutivista", ou seja, uma prática educativa que reproduz as relações de exploração capitalista.

Em contraposição a este tipo de prática, a perspectiva que defendemos nesse estudo visa o enfrentamento das práticas educativas superficiais e de senso comum que permeiam o currículo escolar, uma vez que não se configuram como síntese de múltiplas determinações (SAVIANI, 2005); circunstâncias estas que se traduzem em tematizações ambientais que legitimam as relações de exploração capitalista, causadoras dos problemas ambientais. Esta contraposição visa encontrar caminhos para a superação dessas práticas, a partir do debate dos princípios da EA na perspectiva crítica.

Neste ponto surge o grande problema e desafio para a EA crítica da forma como a compreendemos: seus princípios devem pautar-se em ações que contribuem para superação do modo produção capitalista, principal causador dos problemas ambientais, segundo nossa interpretação. Nesse sentido, é importante destacar que as práticas educativas ambientais da vertente histórico crítica, que se esforçam para implementar um processo educativo que empreende uma reflexão crítica sobre a realidade objetiva, configuram-se numa proposta formativa que contribui para promover o desenvolvimento da consciência filosófica, demanda legítima e necessária ao processo educativo escolar.

O relativismo, que por vezes encontramos em algumas práticas de EA, em nome de que "qualquer ação é válida", prejudica processos mais consistentes do ponto de vista sócio-histórico, em relação à educação escolar, em geral, e à EA especificamente. Consideramos estas ações como atitudes pontuais e fragmentadas do currículo, geralmente praticadas por meio de "comemorações" como o Dia da Árvore, Dia do Índio, Dia do Meio Ambiente, Dia da Água etc. Também as propostas de algumas ONGs, empresas privadas e grande mídia, com caráter genérico e superficial, como, por exemplo, os movimentos $O$ Dia Mundial Sem Carro, A Hora do Planeta: 60 minutos no escuro etc. Essas ações, em geral, impedem reflexões mais consistentes e consequentes sobre os problemas ambientais, contribuindo para camuflar as causas da degradação ambiental nas sociedades capitalistas atuais.

Do ponto de vista sócio-histórico, tais práticas se inserem naquilo que Saviani (2007) chamou de "senso comum educacional". Neste estudo, o autor propõe que os professores superem o senso comum educacional pela consciência filosófica, isto é, que eles partam da realidade empírica do "que-fazer" educativo e, através de reflexões sobre os processos em questão, atinjam a consciência filosófica. Podemos dizer, então, que o autor nos orienta a superar, pelo movimento de ação-reflexão-ação, a tendência de fazer do processo educativo uma ação que separa a prática da teoria na educação escolarizada das crianças, jovens e adultos.

Orientados por esse autor, entendemos que o contexto de organização da escola pública aponta para a necessidade de formação pedagógica dos professores - no caso estudado, daqueles que vão assumir o trabalho educativo ambiental - que possibilite o desenvolvimento de atitudes de interpretação que, partindo da realidade imediata (senso 
comum educacional), busque fundamentação teórica para se pensar essa realidade educativa (abstrações promovidas pelo movimento do pensamento), para desenvolver a autonomia intelectual necessária à construção da consciência filosófica (a compreensão da realidade educacional plenamente compreendida: o concreto pensado).

O processo formativo para os professores em EA, compreendido por nós, busca a "passagem" do senso comum para a consciência filosófica pela reflexão crítica que o professor pode realizar de sua prática educativa. Nesse sentido, acreditamos que o método materialista histórico-dialético oferece a essa formação possibilidades teóricas e metodológicas, pois,

Com efeito, a lógica dialética não é outra coisa senão o processo de construção do concreto de pensamento (ela é uma lógica concreta) ao passo que a lógica formal é o processo de construção da forma de pensamento (ela é, assim, uma lógica abstrata). Por aí, pode-se compreender o que significa dizer que a lógica dialética supera por inclusão/incorporação a lógica formal (incorporação, isto quer dizer que a lógica formal já não é tal e sim parte integrante da lógica dialética). Com efeito, o acesso ao concreto não se dá sem a mediação do abstrato (mediação da análise como escrevi em outro lugar ou détour de que fala Kosik). Assim, aquilo que é chamado de lógica formal ganha um significado novo e deixa de ser a lógica para se converter num momento da lógica dialética. A construção do pensamento se daria, pois, da seguinte forma: parte-se do empírico passa-se pelo abstrato e chega-se ao concreto (SAVIANI, 2007, p.4).

Assim, com as orientações teóricas e metodológicas do método dialético, podemos pensar a relação entre Formação de Professores e EA, buscando sustentação na proposta pedagógica fundamentada no pensamento marxista, dentre as quais se destaca a "Pedagogia Histórico-Crítica". Destacamos que, por considerarmos que a EA escolar tem como principal agente o professor, focamos nossas discussões na Formação de Professores, um campo muito fecundo dos estudos da educação, mas, segundo nossa percepção, ainda pouco explorado na formação dos educadores ambientais. Neste sentido, cabe ponderar que, ao utilizarmos a designação "educadores ambientais", estamos destacando aqueles professores que tematizam o ambiente em suas práticas educativas. Não se trata, pois, de confundir o profissional professor com outro tipo de "agente educativo" que se reconheça como educador ambiental na escola, nem de dar ao professor outra identidade, pois isso descaracterizaria e fragmentaria os elementos constituintes do "ser professor".

Com essas preocupações, consideramos que a Formação de Professores para a inserção da EA na escola, tendo a Pedagogia Histórico-Crítica como referencial teórico, qualifica a EA crítica, pois:

A pedagogia histórico-crítica vai tomando forma à medida que se diferencia no bojo das concepções críticas; ela diferencia-se da visão crítico reprodutivista, uma vez que procura articular um tipo de orientação pedagógica que seja crítica sem ser reprodutivista. Esta colocação parece-me importante em boa parte dos debates que se travaram e das objeções que se levantaram a essa tendência, que acabaram desconsiderando que ela está além do crítico-reprodutivismo, e não aquém. (SAVIANI, 2005, p. 65). 
Nesta perspectiva, os saberes para a Formação de Professores, inclusive como educadores ambientais, têm origem nas práticas educativas focadas nas relações sociais historicamente estabelecidas pelos sujeitos nas sociedades. A pedagogia crítica, de abordagem não reprodutivista, pode contribuir para uma EA que propõe enfrentar os problemas socioambientais resultantes do modo de produção capitalista, produzidos e concretizados socialmente ao longo da história.

A Formação de Professores como educadores ambientais inspirada nesta concepção, cria possibilidades para que o professor assuma a posição de agente social e político; é assim que compreendemos a superação do "senso comum educacional" pela "consciência filosófica" (SAVIANI, 2007). Nessa perspectiva, a Formação de Professores implica em instrumentalizar criticamente os sujeitos para a ação e superação dos problemas socioambientais oriundos do atual modelo de desenvolvimento, numa perspectiva de transformação histórica. É ainda oportuno destacar que, os processos educativo-formativos, inspirados na perspectiva teórica da Pedagogia Histórico-Crítica, encontram-se na perspectiva da EA crítica, pois:

[...] se a educação é mediadora na atividade humana, articulando teoria e prática, a educação ambiental é mediadora da apropriação, pelos sujeitos, das qualidades e capacidades necessárias à ação transformadora responsável diante do ambiente em que vivem. Podemos dizer que a gênese do processo educativo ambiental é o movimento de fazer-se plenamente humano pela apropriação/transmissão crítica e transformadora da totalidade histórica e concreta da vida dos homens no ambiente (TOZONI-REIS, 2007, p. 218).

Um dos desafios que se coloca à Formação de Professores para a EA nessa perspectiva é a "tarefa intelectual de formular teoricamente na prática, pela práxis, o compromisso e o comprometimento de criar condições para uma ruptura com as relações sociais determinadas pelo capitalismo na escola" (TEIXEIRA, 2009).

Com base nessas reflexões, problematizamos a Formação de Professores para pensar a EA que vem se (re)produzindo na educação escolar. Muitas são as propostas e abordagens nessa formação, no entanto, consideramos necessário questionar os modelos de Formação que enfatizam a perspectiva da racionalidade técnica e prática, entendendo que elas tratam a relação entre teoria prática de forma ainda insuficiente, além de serem reforçadas pelas políticas públicas que enfatizam o desenvolvimento de habilidades e competências, dificultando o desenvolvimento da EA crítica da forma como a compreendemos. Delimitamos, desta maneira, o problema para análise neste estudo: " $A$ formação de professores para a inserção da EA na escola é, em geral fundamentada por concepções de formação de professores que não implicam na reflexão teórica sobre a prática didático-pedagógica, de forma a dar conta das contradições da realidade escolar que reflete e reproduz as contradições da sociedade atual".

Desta forma, este artigo contextualiza e problematiza a Formação de Professores, considerando sua possível articulação com a EA no âmbito escolar, sob a perspectiva da Pedagogia Histórico-Crítica, discutindo os impedimentos e as limitações das ações de caráter ambiental que se mostram fragmentadas e pontuais ao serem permeadas por estratégias que separam a teoria da prática, desvalorizando a primeira e esvaziando a segunda. Para isso, avançamos com o objetivo de apresentar uma análise crítica sobre as bases que fundamentam as principais concepções de Formação de Professores e, a partir disto, pensá-la identificando as contradições da prática pedagógica na educação básica, visando contribuir para com o seu aprimoramento e convertendo o professor em um 
profissional comprometido com as classes sociais menos favorecidas, que sofre as principais consequências da crise socioambiental atual.

A expectativa é apresentar, em forma de síntese, de primeiras aproximações, nosso esforço em produzir conhecimentos para a construção de uma concepção para a Formação de Professores como educadores ambientais na perspectiva sócio-histórica.

\section{Formação de Professores e a EA na escola pública: contextualização e problematização sob a perspectiva da Pedagogia Histórico-Crítica.}

A produção de conhecimentos na área da educação no Brasil dá destaque a estudos que discutem a Formação de Professores. Temos observado o crescimento exponencial do número de publicações em congressos, periódicos, livros, bem como a discussão e a produção de pesquisas em programas de pós-graduação em educação sobre este tema. A produção acadêmica sobre esse tema é intensa e reconhecidos pesquisadores na área tem produzido metapesquisas do tipo "Estado da Arte", cujo foco volta-se para a formação inicial e continuada de professores. Destaca-se, a título de exemplo, a pesquisa realizada por André et al. (1999), que analisou os periódicos da área de educação no período de 1990-1997 e concluiu que, a tendência sobre a formação continuada de professores se concentra em três aspectos:

[...] a concepção de formação continuada, propostas dirigidas ao processo de formação continuada e o papel dos professores e da pesquisa nesse processo. O conceito predominante de formação continuada nos periódicos analisados é o do processo crítico-reflexivo sobre o saber docente em suas múltiplas determinações. (ANDRÉ et al., 1999, p. 305).

Por formação continuada, os pesquisadores concebem "formação em serviço, enfatizando o papel do professor como profissional e estimulando-o a desenvolver novos meios de realizar seu trabalho pedagógico com base na reflexão sobre a própria prática" (ANDRÉ et al., 1999, p. 308). O estudo revelou que, enquanto alguns pesquisadores concebem a formação continuada como treinamento, cursos, seminários etc., outros a entendem como um processo, definindo-a como prática reflexiva na escola. Outros pesquisadores e formadores a concebem como prática reflexiva do cotidiano escolar e como saberes, que emergem da experiência docente, estes articulados a dimensões sociopolíticas mais amplas.

No que tange à Formação de Professores que trabalham com EA na escola pública, observamos nos estudos de Maia (2011) e Teixeira (2009) que os fundamentos teóricos e metodológicos que caracterizam e fundamentam a produção acadêmica sobre a formação de professores como educadores ambientais "não é uma questão" para o professor. Este mesmo resultado também foi constatado na pesquisa/FAPESP, intitulada, Fontes de Informação dos Professores da Educação Básica: subsídios para a divulgação de conhecimentos acadêmico-científicos sobre EA, cujos dados foram obtidos coletivamente, por meio de observações realizadas em escolas e entrevistas com 277 professores, em 14 municípios da região central do Estado de São Paulo, constando que:

[...] as fontes de informação buscadas pelos professores entrevistados para inserir a EA no trabalho escolar, assim como as atividades desenvolvidas e as dificuldades encontradas, na perspectiva de sua 
própria formação, não são adequadas nem suficientes para que reflitam sobre sua própria prática, pois não fornecem elementos consistentes para a elaboração do saber específico que essa inserção exige. Não seria exagero dizer que esses elementos da inserção da EA nas escolas, revelados em nosso estudo pelos entrevistados, vulgarizam e generalizam os conhecimentos teóricos, específicos e práticos necessários para essa inserção. (TOZONI-REIS; TEIXEIRA; MAIA, 2011, p. 9).

Esses dados auxiliam a pensar a Formação de Professores e a EA, pois revelam diversos elementos que dificultam o processo de formação permanente dos professores da escola pública, embora esses problemas não possam ser atribuídos diretamente aos professores que atuam na educação básica. Sabemos como a prática educativa dos professores realiza-se em condições complexas de exploração de trabalho e banalização do conhecimento, e que esses são elementos fundamentais para a compreensão da qualidade do ensino, em especial da qualidade do ensino público.

No que diz respeito aos autores e seus referenciais, as pesquisas desenvolvidas na modalidade Estado da Arte indicam que o conceito de formação continuada, como prática reflexiva e pela reflexão sobre o seu fazer e seu saber fazer, fundamenta-se nos estudos de Schön, Perrenoud, Zeichner, Nóvoa, Marcelo Garcia e Perez Gómez. Já em relação ao conceito de formação continuada para além da prática reflexiva, num contexto sóciopolitico-econômico-cultural mais amplo, destaca-se os estudos de Castoriadis, Giroux, Maclaren e Apple (ANDRÉ, 2002). Concluímos deste modo, que esses autores fundamentam a maior parte das pesquisas sobre Formação de Professores no Brasil e, de certa forma, afirmamos que eles aparecem - embora de forma muito tênue - na pesquisa em EA no país.

Dentre esses referenciais da pesquisa na área de Formação de Professores, Contreras (2002), ao discutir a questão da autonomia dos professores, revisa e destaca as contribuições e os limites das principais formulações. Sua crítica incide inicialmente na ideia do professor como técnico; passa pela proposta de um profissional reflexivo, elaborada por Shön; e avança até as formulações teóricas de Habermas. Esse autor problematiza as ideias do professor técnico, do reflexivo, como artista; e do pesquisador e do professor como intelectual crítico (MIANUTTI, 2010). Não obstante, é importante destacar que em muitos estudos sobre formação de professores, "inclusive os que defendem a "racionalidade prática" (professor reflexivo) e a "racionalidade crítica" (professor como intelectual crítico), o combate é contra a racionalidade técnica (professor como técnico)" (Op. Cit., p. 34).

Afirmamos que, de forma geral, a literatura sobre Formação de Professores denuncia a perspectiva da racionalidade técnica, entendendo que esta separa teoria e prática da pesquisa em educação da realidade escolar, formando professores que desconhecem a complexa realidade da escola. Neste sentido, a formação técnica não contribui para a construção de conhecimentos e métodos que possibilitem o ato didáticopedagógico, para dar conta das contradições da escola, que reflete e reproduz as contradições da sociedade.

Assim, esta perspectiva não leva em conta a organização do trabalho didático na escola pública e as condições de exploração do trabalho docente, pois não considera a realidade como ponto de partida. Tal constatação evidencia-se também no estudo " $O$ que fazem as escolas que dizem que fazem Educação Ambiental", realizado pelo MEC/INEP (TRAJBER; MENDONÇA, 2006) em escolas de Ensino Fundamental e Médio de todo o país. O documento destaca as condições de produção da escola pública, especialmente no que tange às condições objetivas e aos aspectos relativos à: 
[...] falta de organização e estruturação da ação escolar para a inserção da Educação Ambiental, localizados num campo de preocupações materiais, na medida em que, as principais dificuldades apontadas pelo documento foram: a falta de tempo para o planejamento e realização de atividades extracurriculares; a precariedade de recursos materiais; e a falta de recursos humanos qualificados. (TRAJBER; MENDONÇA, 2006, p. 180).

É preciso considerar que a Formação de Professores da educação básica não leva em conta as precárias condições de trabalho, a desvalorização social da docência e a baixa remuneração, que criam condições adversas às iniciativas de formação. Se examinarmos todas essas condições, analisando-as como síntese de múltiplas determinações, veremos que os esforços investidos se transformam, em geral, em um modelo de formação que, na prática, valoriza o treinamento ou capacitação de habilidades e competências que, mesmo utilizando uma fundamentação teórico-metodológica apontada pelas pesquisas que discutem o estado da arte da Formação de Professores, resultam na formação técnica que valoriza a prática sem a teoria, sem a reflexão teórica e crítica do trabalho didático.

Considerando a realidade objetiva da escola pública, percebemos que o professor é concebido como técnico e entendido como um realizador de tarefas, que deve ser treinado para resolver problemas relacionados à prática. Esta concepção de professor está estritamente vinculada à racionalidade técnica que, na sociedade neoliberal, assume uma perspectiva prático-utilitarista expressa por meio de expressões do saber-aprender e saberfazer.

Neste sentido, as propostas de formação de professores que se pautam nas políticas de formação vigentes, não se revelam adequadas para que eles pensem e reflitam de forma mais aprofundada sobre a prática, pois não fornecem elementos teórico-práticos consistentes para fundamentar suas ações. Pode-se dizer, portanto, que essas concepções vulgarizam e generalizam os conhecimentos teóricos, específicos e práticos, que são necessários para o trabalho didático-pedagógico do professor.

Nesse contexto, as questões referentes à EA têm pouco espaço na organização do trabalho na escola pública, sendo relegadas a projetos pontuais como datas comemorativas, além de outras tão fragmentadas quanto essas, levando à compreensão, por parte dos professores, gestores, estudantes e pais, que estas questões são secundárias no conteúdo escolar.

Nessa inserção fragmentada da EA na escola, a relevância dos elementos sóciohistóricos é minimizada. Ao considerarmos essa tendência, identificamos que, na Formação de Professores, a temática ambiental é negligenciada. Apesar das pesquisas desenvolvidas no Brasil nos últimos anos, não podemos afirmar que temos formação inicial e continuada de professores como educadores ambientais em condições de enfrentar os muitos e variados problemas presentes na escola, tampouco de converter esta instituição e seus profissionais em agentes disseminadores de ideias que permitam uma nova sociedade, mais justa, igualitária e sustentável, portanto, formada por sujeitos plenos e emancipados, cuja relação com o ambiente seja mais equilibrada.

Assim, a abordagem técnico-instrumental na formação de professores é parte da estrutura e do funcionamento dos cursos de formação, em especial dos de formação continuada (a formação inicial se dá nas licenciaturas, em que encontramos diferentes e variadas propostas teórico-metodológicas), que estabelecem como tônica a (de)formação de um professor que cumpra tarefas preestabelecidas em competências, expropriando o 
professor do conhecimento, controlando-o e o escravizando por meio do controle de suas atividades práticas.

$\mathrm{Na}$ apresentação do livro de Contreras, Autonomia de professores, Pimenta (2002, p.18) alerta para o fato desta mercantilização da profissão docente:

[...] no que se refere ao tema das novas configurações do trabalho, o não emprego é uma das características da sociedade globalizada das informações. Nesta, o trabalho autônomo descarta as conquistas trabalhistas, que são dispendiosas para os empregadores, incluindo o Estado. Para conseguir trabalho e sobreviver, o trabalhador desempregado necessita buscar, por sua conta, requalificações. E aí se pode compreender a imensa valorização hoje conferida aos programas de formação contínua, transformando a educação em um grande mercado.

Não é exagero, pois, concluirmos que os cursos de formação de professores, nesta perspectiva, caminham para a desprofissionalização - ou deformação - do professor. Ao invés de priorizarem a formação com centralidade nas metodologias e nas teorias necessárias para a apropriação de conhecimentos que fundamentem a prática do professor, o que supõe uma sólida formação, percebe-se nestes cursos e nas políticas públicas, a redução dos saberes necessários ao exercício da docência em competências técnicas e no desenvolvimento de competências e habilidades. Desta forma, Pimenta (2002, p. 21) destaca:

[...] competências, no lugar de saberes profissionais, desloca do trabalhador para o local de trabalho a sua identidade, ficando este vulnerável à avaliação e controle de suas competências, definidas pelo 'posto de trabalho'. Se não se ajustam ao esperado, facilmente poderá ser descartado.

Percebe-se que a autora refere-se também à Formação de Professores pautada na racionalidade técnica, formação que reproduz o modelo neoliberal por meio do desenvolvimento de competências técnicas para a execução de metas e objetivos preestabelecidos. A partir desta concepção estritamente técnica, o professor cumpre metas, atinge objetivos, alcança índices pré-estabelecidos e, entre outros atributos, transforma-se em um executor de tarefas. Esta concepção de competências contribui para a alienação do professor, que fica preso ao "senso comum educacional", e não lhe permite alcançar a "consciência filosófica" (SAVIANI, 2007), necessária à inserção interdisciplinar da EA na escola pública.

Esse processo de (des)qualificação dos professores reflete diretamente em sua preparação - ou não - para lidar com temas recentes que se apresentam na escola, tais como a EA, a educação para cidadania, a educação das relações de gênero e em sexualidades, entre outros temas; uma vez que esta instituição é sempre alvo de proposições relacionadas aos problemas da sociedade. Verifica-se, a despeito de sua formação fragmentada e de abordagem técnico-instrumental, a responsabilização da escola e do professor no sentido de dar respostas a essas temáticas; imputam-se, numa visão redentora da educação e da escola, funções de resolver problemas gerados pelo modo de produção vigente sem, sequer, prepará-los para compreendê-los.

Tudo isso contribui para aumentar a confusão entre o que é "o que fazer" do professor: organizar a apropriação dos conhecimentos produzidos socialmente e acumulados historicamente pelo gênero humano aos sujeitos singulares, ou ensinar a resolver problemas de forma prática e utilitária para satisfazer as necessidades do 
mercado? Sabemos que entre uma e outra questão, muitas outras se colocam. No entanto, consideramos que a escola, tampouco o professor, são capazes de realizar semelhante tarefa. Residirá aí o motivo do fracasso escolar como vemos no Brasil, ou será outra a causa?

\section{Um referencial para se pensar a Formação de Professores para a EA na perspectiva histórico-crítica}

Para contribuir com os esforços necessários para a superação dessas dificuldades, consideramos que a Formação de Professores para a inserção da EA na escola pode proporcionar condições para que eles pensem sobre a complexidade de sua ação educativa, compreendendo criticamente a perspectiva dominante de execução de tarefas práticas que expressa a desvinculação entre a prática docente e a pesquisa; a escola pode ir além da competência técnica; a Formação de Professores pode ser pautada no compromisso político com as classes menos favorecidas. Consideremos ainda que os professores das escolas públicas no Brasil, hoje, na maioria das vezes, são oriundos destas classes sociais, e devem trabalhar a para sua emancipação.

Outro aspecto a considerar é a ideia do professor reflexivo, muito conhecida atualmente. Nesse sentido, é necessário aprofundarmos a compreensão do que diferencia e significa reflexão. Enquanto a proposta do professor reflexivo, que reflete sobre a própria prática, carece de melhor compreensão da reflexão como uma ação da práxis, como um processo que exige a unidade entre a teoria e a prática, a proposta da pedagogia histórico crítica entende reflexão como:

Um pensamento consciente de si mesmo, capaz de avaliar-se, de verificar o grau de adequação que mantém com dados objetivos, de medir-se com o real. Pode aplicar-se às impressões e opiniões, aos conhecimentos científicos e técnicos, interrogando-se sobre o seu significado. $\mathrm{O}$ ato de retomar, reconsiderar dados disponíveis, revisar, vasculhar numa busca constante de significados. É examinar detidamente, prestar atenção, analisar com cuidado. (SAVIANI, 2007, p. 20).

Reflexão, então, pressupõe um conjunto de conhecimentos sistematizados que uma vez assimilados, permite ao ser humano compreender e atuar sobre sua realidade. Sem esses conhecimentos, que emergem de um processo mais complexo de formação, e, portanto, diretamente relacionado ao gênero humano, não é possível uma reflexão no sentido que compreende esse trabalho. Reflexão vista como "um ato filosófico e para tal deve ser radical, rigorosa e de conjunto" (SAVIANI op. cit.). Radical no sentido de buscar as raízes dos problemas sobre o qual se propõe a reflexão; rigorosa em termos do método, de partir da realidade imediata e buscar abstrações, questionando a compreensão que o senso comum tem da realidade, para incorporá-lo, mas também superá-lo. Superar a compreensão do senso comum não significa negá-lo e desprezá-lo, mas questioná-lo pelo exercício dialético de interpretação da realidade. A reflexão, assim, abre as possibilidades para as ações, já que evidencia o problema em seu contexto e, dessa maneira, possibilita o enfrentamento deste. Esse exercício é a reflexão-ação, a integração teoria e prática, a práxis. Contudo, é importante compreender que:

[...] os aspectos anteriormente expostos não são categorias autosuficientes que se justapõem numa somatória suscetível de caracterizar, pelo efeito mágico de junção, a reflexão filosófica. A profundidade 
(radicalidade) é essencial à atitude filosófica do mesmo modo que a visão de conjunto. Ambas se relacionam dialeticamente por virtude da íntima conexão que mantêm com o mesmo movimento metodológico, cujo rigor (criticidade) garante ao mesmo tempo a radicalidade, a universalidade e a unidade da reflexão filosófica. (SAVIANI, 2007, p. 21).

Para que a educação emancipatória concretize-se, é preciso ações que vão além da escola e dos professores. É necessária a participação ativa da sociedade e de suas instituições, para que a escola possa se organizar na perspectiva da educação emancipatória. Todavia, é preciso considerar a participação da escola em todo esse processo, como resposta a sua descaracterização como instituição social formadora e responsável pela difusão do saber sistematizado. É importante, nesse sentido, que o professor assuma para si a responsabilidade de resgatar seu papel fundamental na escola, empreendendo esforços para a superação do processo de proletarização a que está submetido, bem como a superação da burocratização do processo pedagógico imposto pelo modelo político, social e econômico de inspiração neoliberal.

Sabemos como os professores estão sobrecarregados de atividades que lhes são impostas, mas é necessário considerar que essa carga excessiva de trabalho é o que descaracteriza a prática pedagógica como práxis educativa. As múltiplas funções a que estão submetidos os professores emergem da lógica produtivista do mercado de que o profissional deve ser multitarefas.

Ao realizar seu papel, o professor não percebe a necessidade de romper com essa relação imediata entre pensamento e ação, o que o leva à rejeição da reflexão filosófica e das teorias educacionais mais elaboradas. O professor vê a si mesmo como um indivíduo prático, que não precisa de teorias, já que é na prática que se resolvem os problemas ou ainda em experiências próprias já vividas ou relatadas por colegas de profissão.

Todo e qualquer curso de formação de professores numa perspectiva mais crítica e emancipatória, deve problematizar essas questões com o objetivo de romper com essa lógica, levando o professor a se apropriar do saber acumulado historicamente, problematizando que o conhecimento da experiência, da memória, do saber prático não são suficientes para superar as ilusões do senso comum educacional. Esse confronto, fundamentado pelas teorias pedagógicas mais elaboradas, como pensamos ser a pedagogia histórico-crítica, criará condições para a realização do que propomos para transformar a escola em um espaço social crítico, emancipado e emancipatório.

Essas considerações têm como objetivo contribuir na organização de processos formativos para o professor construir uma prática emancipatória, que busque enfrentar e superar a lógica do capital imposta por políticas públicas que se submetem à lógica do mercado, explicitada pelos livros didáticos, pela mídia, pela formação precária dos professores, pela burocratização da escola, etc. É neste sentido que compreendemos a inserção da EA na formação de professores.

\section{Concluindo sobre a formação de professores e a EA}

A produção de conhecimentos sobre Formação de Professores para a educação básica pode contribuir para a inserção da EA na escola pública. Nesse sentido, objetivamos, neste estudo, empreender uma análise crítica das bases que fundamentam 
essas propostas de formação, para a aproximarmos de uma possível concepção para formação de educadores ambientais na perspectiva sócio-histórica.

As práticas educativas do professor para a EA, da forma como a compreendemos, configuram-se em ações intencionais que partem da realidade social para, a partir de um processo crítico e reflexivo, transformarem-se em conhecimentos elaborados que possam ser socializados por um processo educativo complexo e dinâmico.

Os entraves para uma práxis ambiental na escola foram identificados por nós como consequências de um processo de dilapidação das condições físicas e psíquicas dos professores e da inadequação do processo de gestão da escola, o que se reflete diretamente nas propostas de formação de professores. Em outras palavras, a EA fracassa porque também fracassam a educação, os professores, as políticas públicas de sua formação, em função da desumanização imposta pelo modo de produção capitalista em sua vertente mais nefasta, o neoliberalismo na economia, o pós-modernismo na cultura e na educação e pragmatismo e o neopragmatismo na política. Problematizamos neste estudo que, nessas condições, o trabalho dos professores sofre um processo de alienação. Esse processo é um fenômeno pelo qual o trabalhador - desenvolvendo a sua atividade em condições que lhe são impostas pela fragmentação do trabalho, que se origina na divisão da sociedade em classes - é sacrificado, pois se encontra afastado das decisões sobre o processo e o produto do seu próprio trabalho (MAIA, 2011).

Embora existam pressões em diversos âmbitos da sociedade para a implementação da EA na escola, observamos que as práticas educativas ambientais seguem fragmentadas e pontuais. Arriscamo-nos aqui a identificar esse fenômeno como resultado de ações externas à escola que, além de não considerarem as condições de exploração do trabalho docente, não se articulam com o processo de Formação Permanente de Professores. Parece que as pesquisas produzidas no âmbito da EA não conseguem dialogar, de forma mais aprofundada, com as pesquisas produzidas sobre Formação de Professores. Esta distorção compromete o enfrentamento pedagógico da questão ambiental ao dicotomizar a relação entre teoria e prática na Formação dos Professores para inserir a EA na escola.

Se a especificidade do trabalho intelectual exige uma profunda relação entre teoria e prática, exige também que a práxis seja o fundamento do trabalho docente. Trouxemos, neste texto, algumas reflexões sobre como os processos de proletarização da profissão docente - que implicam na separação teoria e prática - vêm aviltando a prática pedagógica. Compreendemos que a Formação Permanente de Professores, para desenvolverem práticas educativas ambientais na escola, pode auxiliar na superação dessa situação e dos processos formativos, articulando-os, radicalmente, à teoria e à prática educativa ambiental. As reflexões, empreendidas no decorrer deste estudo, indicaram a importância da superação do reducionismo com que muitas das ações educativas ambientais tratam a relação teoria e prática, e desta forma, supervalorizando a prática em detrimento da teoria ou considerandoa como prática educativa imediata. Mas, é também importante enfrentar o reducionismo oposto: a super-valorização da teoria em detrimento da prática.

Com essas preocupações, considerou que, para a superação dos reducionismos com que nos deparamos na ação educativa e, ao mesmo tempo, na ação investigativa de produção de conhecimentos - principalmente no mundo acadêmico - é possível tomarmos como principal referência a "práxis". Compreendida em sua forma plena, ela permite avançar nessa superação, contribuindo para a investigação e a ação educativa ambiental, ao reconduzir como fundamental o pensamento e a ação na construção, intencional e consciente da inserção da EA na educação escolar. Ainda contribui, naquilo que lhe é mais específico: a prática, pensada e refletida, sobre a realidade com objetivos transformadores. 
Consideramos que a Formação de Professores no contexto atual brasileiro, carece de perspectivas que permitam ao professor buscar a "consciência filosófica" (SAVIANI, 2007). Assim, inserir a busca desta consciência nos cursos de Formação de Professores para a inserção da EA na escola permitiria, aos professores, apropriar-se da realidade prática, compreendendo-a como síntese de múltiplas determinações, superando a concepção pseudo-concreta por uma visão sintética da realidade. Essa inserção, em nossa avaliação, permitirá duas apropriações significativas em relação às práticas educativas ambientais. A primeira refere-se à compreensão das determinações da prática social em relação à problemática ambiental, seus elementos causais e as consequências destes, ampliando sua forma de ver a realidade (concepção teórica). A segunda é a percepção que é possível intervir na realidade socioambiental, no sentido de também aprofundar a compreensão do real que possuímos no plano genérico das relações, entre a sociedade e a natureza.

Acreditamos ser possível entender que há condições de instrumentalizar professores e estudantes e, dessa forma, voltar à realidade socioambiental, identificado-a como síntese das determinações antes não percebidas, analisadas e, portanto, não compreendidas. Essa condição expõe que o processo pedagógico, em alguma medida, influenciará o professor para pensar seu entorno de forma crítica, contribuindo para processos emancipatórios na escola.

Entendemos que a inserção da EA na escola pressupõe um conjunto de elementos a serem considerados, muito além das práticas ambientais por si mesmas. Para isso, consideramos como possibilidade formativa teorizar os saberes relacionados ao materialismo histórico dialético, cuja referência principal está em partir da prática social, ascender à teoria e retornar à prática social, concretizando, assim, uma práxis revolucionária (SAVIANI, 2005) para pensarmos as questões ambientais nos processos educativos escolares.

\section{Referências}

ANDRÉ, M. (org.) Formação de professores no Brasil (1990-1998). Brasília: MEC/ Inep/Comped, 2002.

ANDRÉ, M. et al. Estado da Arte da Formação de Professores no Brasil. Educação \& Sociedade, Campinas, ano XX, n. 68, dez., 1999.

CONTRERAS, J. A autonomia de professores. São Paulo: Cortez, 2002.

GRÜN, M. Ética e educação ambienta: A conexão necessária. 11 ed. Campinas/SP: Papirus, 2007.

LOUREIRO, C. F. B. Trajetória e fundamentos da educação ambiental. São Paulo: Cortez, 2004.

MAIA, J. S. da S. Educação ambiental crítica e formação de professores: Construção coletiva de uma proposta na Escola Pública. Tese (Doutorado em Educação para a Ciência). 250 p. Faculdade de Ciências / Universidade Estadual Paulista Júlio de Mesquita Filho, Bauru, 2011.

MIANUTTI, J. Uma proposta de formação continuada de professores de Biologia em Mato Grosso do Sul: de manuais didáticos a obras clássicas no estudo da evolução biológica. Tese [Doutorado em Educação para a Ciência]. Faculdade de Ciências / Universidade Estadual Paulista Júlio de Mesquita Filho, Bauru, 2010. 
PIMENTA, S.G. Apresentação à edição brasileira. In: CONTRERAS, José. Autonomia de professores. Tradução de Sandra Trabucco Valenzuela; revisão técnica, apresentação e notas à edição brasileira Selma Garrido Pimenta. São Paulo: Cortez, 2002. pp. 11-21.

SAVIANI, D. Educação: do senso comum à consciência filosófica. 17 ed. Campinas/SP: Autores Associados, 2007.

SAVIANI, D. Pedagogia Histórico-Critica. Campinas, Autores Associados, 2005.

TRAJBER, R.; MENDONÇA, P. R. (org) O que fazem as escolas que dizem que fazem educação ambiental. Brasília: MEC/Secad, 2006.

TEIXEIRA, L. A. Análise dos Projetos Ambientais desenvolvidos em um bairro de Bauru (SP) sob a perspectiva educativa. 2009. 223 f. Dissertação (Mestrado em Educação para a Ciência) - Universidade Estadual Paulista, Faculdade de Ciências, Bauru, 2009.

TOZONI-REIS, M. F. C. Contribuições para uma pedagogia crítica na educação. In: LOUREIRO. C. F. B. A questão ambiental no pensamento crítico: natureza, trabalho e educação. Rio de Janeiro: Quartet, 2007, p. 177-221.

TOZONI-REIS, M. F. de C. Educação ambiental: natureza, razão e história. CampinasSP: Autores Associados, 2004.

TOZONI-REIS, M. F. C; TEIXEIRA, L. A; MAIA, J. S. da S. As publicações acadêmicas e a educação ambiental na escola básica. Trabalho Completo, 2011. Anais ANPED Associação Nacional de Pós-Graduação e Pesquisa em Educação. Natal, RN. Disponível em: <http://www.anped.org.br/app/webroot/34reuniao/images/trabalhos/GT22/GT22257\%20int.pdf $>$. Acesso em: 11 fev. 2012.

Recebido: abril-14 Aprovado: outubro-14 